\title{
A NEUROCIÊNCIA NA FORMAÇÃO DE PROFESSORES: UM ESTUDO DA REALIDADE BRASILEIRA
}

\author{
Márcia Gorett Ribeiro Grossi * \\ Aline Moraes Lopes ** \\ Pablo Alves Couto ${ }^{* * *}$
}

\begin{abstract}
RESUMO
Conhecer o funcionamento, potencialidades e limitações do sistema nervoso possibilitam atender as demandas do educador frente às dificuldades de aprendizagem, levando a uma contribuição positiva na prática pedagógica. Por isso a importância de perceber os fundamentos sobre neurobiologia cognitiva, necessários no processo ensino e aprendizagem. Nesta perspectiva, o objetivo desta pesquisa foi verificar se os cursos de Pedagogia e dos Programas Especiais de Formação Pedagógica de docentes no Brasil têm incorporado em suas propostas pedagógicas os conhecimentos sobre a neurociência. Assim, foram realizadas análises nas matrizes curriculares desses cursos. Complementando o estudo, foi feita uma consulta ao banco de Teses e Dissertações da Capes, para identificar as publicações nacionais acadêmicas sobre essa temática. Os resultados permitem afirmar que a neurociência cognitiva na área educacional ainda não é uma realidade, haja vista a falta de disciplinas relacionadas com a neurociência na maioria das matrizes curriculares dos cursos pesquisados. Os dados, portanto, indicam a necessidade de uma revisão nos currículos dos profissionais da Educação. Analisando a produção nacional sobre a neurociência na educação, percebe-se que a pesquisa sobre este tema encontra-se tímida, embora exista um interesse cada vez maior nos últimos dez anos.
\end{abstract}

Palavras-chave: Prática pedagógica. Neurociência. Processo ensino e aprendizagem. Publicações nacionais. Curso de pedagogia.

\section{ABSTRACT \\ NEUROSCIENCE FINDINGS AND TEACHER TRAINING: A STUDY OF BRAZILIAN REALITY}

Understanding the nervous system function, its capabilities and limitations may help educators to solve their demands through new ways of viewing their pedagogical practice when facing learning difficulties. This is why it is important to understand the

\footnotetext{
* Doutora em Ciência da Informação pela UFMG. Mestre em Tecnologia pelo CEFET-MG. Engenheira Eletricista pela PUC-MG. Professora do Depto de Educação e Subcoordenadora do Mestrado em Educação Tecnológica do CEFET-MG. Membro do Grupo de Pesquisa AVACEFET do CEFET-MG. Endereço para correspondência: Av. Amazonas, 7.675 -Nova Gameleira, Belo Horizonte. Minas Gerais. CEP: 30510-000. marciagrossi@terra.com.br

** Mestranda em Educação Tecnológica pelo CEFET-MG. Especialista em PROEJA pelo CEFET-MG. Graduada em Letras pela UFSJ. Membro do Grupo de Pesquisa AVACEFET do CEFET-MG. Endereço para correspondência: Av. Amazonas, 7.675 - Nova Gameleira, Belo Horizonte. Minas Gerais. CEP: 30510-000. adrenalineletras@hotmail.com

*** Mestrando em Educação Tecnológica pelo CEFET-MG. Graduado em Ciências Biológicas pela UFMG. Membro do Grupo de Pesquisa GEMATEC do CEFET-MG. Endereço para correspondência: Av. Amazonas, 7.675 - Nova Gameleira, Belo Horizonte Minas Gerais. CEP: 30510-000. pa.couto@yahoo.com.br
} 
fundamentals of cognitive neurobiology required for teaching and learning processes. In this perspective, the objective of this study was to check whether Pedagogy courses and Special Programs for teacher training in Brazil have incorporated into their pedagogical practice the knowledge of neuroscience. Thus the curricular schedules of these courses were analyzed. In order to complement this study, thesis and dissertations from Capes were also analyzed in an attempt to identify national academic publication on this topic. The results indicate that cognitive neuroscience in education is not yet a reality, given the lack of disciplines related to neuroscience in most curricular courses analyzed. Thereby, it is necessary a revision of the curricula of teacher training courses. When we analyze the national studies on neuroscience and its application in education, it is clear that there are few researches on this topic, although there is a growing interest on it in the last ten years.

Keywords: Pedagogical practice. Neuroscience. Teaching and learning processes. National publications. Pedagogy courses.

\section{Introdução}

O Brasil tem 12,9 milhões de analfabetos, segundo o relatório de 2012 da Pesquisa Nacional por Amostra de Domicílios (Pnad). A responsabilidade por esse índice é decorrente de vários motivos. Dentre eles destacam-se os altos índices de fracasso escolar, que podem ser verificados nos resultados apresentado pelos sistemas de avaliação como a Prova $\mathrm{AB}$, que é uma parceria entre o movimento independente Todos Pela Educação, o Instituto Paulo Montenegro/Ibope, a Fundação Cesgranrio e o Instituto Nacional de Estudos e Pesquisas Educacionais (Inep), a Avaliação da Educação Básica (Saeb) e a Prova Brasil, ambos realizados pelo Inep. Todas essas avaliações têm revelado que no ano de 2011 os alunos que chegam ao $5^{\circ}$ ano do Ensino Fundamental não dominam as competências básicas de leitura, escrita e matemática, principalmente os alunos das escolas públicas. Além desses dados, a empresa Pearson apresentou em 2012 o resultado de uma pesquisa sobre habilidades cognitivas e desempenho escolar em 40 países. O Brasil ficou na penúltima colocação nesta pesquisa, que considera o resultado de testes de matemática, leitura e ciências para alunos dos últimos anos do ensino fundamental, indicando que a alfabetização desses alunos não tem sido plenamente efetivada, contribuindo para o alto índice de analfabetos brasileiros (PEARSON, 2012).

Com base no cenário exposto, acredita-se que uma possibilidade para minimizar o fracasso escolar é aceitar as diversidades presentes nas salas de aula. Os professores precisam estar capacitados para compreender e atender as diferenças cognitivas dos alunos de acordo com os princípios da neurociência, pois o conhecimento do sistema nervoso, fisiológico e patológico ajuda a melhorar as práticas educativas visando à diminuição das dificuldades de aprendizagem (ESCRIBANO, 2007).

Nesta direção argumentativa, a neurociência enquanto um ramo do conhecimento que envolve várias áreas como, por exemplo, a neurologia, a psicologia e a biologia, que possuem como tema comum de pesquisa o sistema nervoso (SN) oferece a possibilidade de entender como ocorre o processo de aprendizagem. Embora, para que a aprendizagem aconteça, seja necessário o diálogo entre a neurociência e a pedagogia, pois esta última é a responsável pelos métodos pedagógicos de ensino. Complementando esse tema, Guerra (2010, p. 4) comenta:

Os avanços das neurociências esclareceram muitos aspectos do funcionamento do $\mathrm{SN}$, especialmente do cérebro, e permitiram a abordagem mais científica do processo ensino e aprendizagem. Funções relacionadas à cognição e às emoções, presentes no cotidiano e nas relações sociais, como dormir, comer, gostar, reconhecer, falar, compreender, ter atenção, esquecer, experimentar, ajudar, lembrar, calcular, planejar, julgar, rir, movimentar-se, trabalhar, emocionar-se, são comportamentos que dependem do funcionamento do cérebro. Educar é aprender também.

E, para entender o que ocorre com o cérebro quando uma pessoa aprende, faz-se necessário realizar releituras dos teóricos da educação, associan- 
do-os aos estudos da neurociência; compreender a biologia do cérebro nas dimensões cognitivas, emocionais, afetivas e motoras; reconhecer que o processo de aprender está relacionado com as bases químicas e físicas na função neural do ser humano; e, como cada ser humano é único, cada cérebro é único e aprende de forma diferente. Portanto, é preciso ensinar de formas diferenciadas. Dentre esses autores, destacam-se: Piaget, com seus estágios de desenvolvimento (sensório-motor, pré-operatório, operatório concreto e operatório formal); Ausubel, com a aprendizagem significativa; Vygotsky e a zona de desenvolvimento proximal, a qual define a distância entre o desenvolvimento real da criança e o desenvolvimento potencial, que representa aquilo que ela tem potencial de aprender; e Markova, com sua teoria das linguagens naturais da mente. Desta forma, a neurociência na sala de aula retoma questões já estudadas por teóricos da psicologia e da educação, trazendo novos olhares sobre estas questões.

Cabe destacar que, de acordo com Metring (2011, p. 3), os neurocientistas:

[...] não estão preocupados em formular receitas, seja para a área educacional, organizacional, médica ou qualquer outra. Estão, sim, preocupados em descobrir, dia após dia, coisas maravilhosas sobre a organização neuronal do ser humano e as disponibilizar para quem queira utilizar seus achados, mas o trabalho de articulação (no nosso caso, os processos de ensino e aprendizagem) precisa ocorrer a partir das necessidades dessas áreas e por profissionais dessas áreas.

A neurociência é compreendida por 6 abordagens:

- Neurociência molecular: investiga a química e a física envolvidas na função neural. Estuda as diversas moléculas de importância funcional no $\mathrm{SN}$;

- Neurociência celular: considera as distinções entre os tipos de células no SN e como funciona cada um respectivamente;

- Neurociência sistêmica: estuda as regiões do $\mathrm{SN}$, de processos como a percepção, o discernimento, a atenção e o pensamento;

- Neurociência comportamental: estuda a interação entre os sistemas que influenciam o comportamento, explica as capacidades mentais que produzem comportamentos como sono, emoções, sensações visuais, dentre outros;

- Neurociência cognitiva: estuda as capacidades mentais mais complexas como aprendizagem, linguagem, memória, planejamento;

- Neurociência clínica: estuda as patologias do SN.

$\mathrm{O}$ foco de investigação desta pesquisa foi a abrangência cognitiva, ressaltando que o objetivo da neurociência na educação não é propor uma nova pedagogia, mas apontar caminhos e metodologias mais adequadas no desenvolvimento da educação.

Nessa perspectiva, objetivou-se verificar se os cursos de Pedagogia e dos Programas Especiais de Formação Pedagógica de docentes no Brasil têm incorporado em suas propostas curriculares os conhecimentos da neurociência, bem como identificar as publicações acadêmicas sobre o tema pesquisado. Para atingir esse objetivo, a metodologia empregada foi a análise de conteúdo em uma abordagem qualitativa com enfoque descritivo, por meio de análises nas matrizes curriculares desses cursos e a consulta ao banco de Teses e Dissertações da Capes (BRASIL, 2013), para identificar as publicações nacionais acadêmicas sobre essa temática.

Nesse contexto, as contribuições deste artigo são relevantes sob dois aspectos: em razão da importância dos estudos sobre a relação entre cognição e processo de ensino e aprendizagem no cenário de educação no Brasil, e também por apresentar dados que indicam que neurociência na educação ainda não é uma realidade nos cursos de pedagogia e nem nos cursos de formação especial de professores.

\section{Anatomia da aprendizagem: como o cérebro aprende}

De acordo com Relvas (2011), existe uma biologia cerebral, uma fisiologia e uma anatomia em um cérebro que aprende. Assim, pode-se pensar em uma anatomia da aprendizagem que envolve a análise e a compreensão da relação entre a cognição, que abrange os mecanismos neurais responsáveis 
pelas funções mentais superiores como a consciência, a imaginação e a linguagem, e o processo de aprendizagem. Em síntese, é o vínculo entre o ato de aprender e as atividades do Sistema Nervoso Central (SNC).

Ainda de acordo com Relvas (2011), o processo de aprendizagem do cérebro está na neurociência celular, destacando neste processo a importância dos neurônios, que têm como função básica receber, processar e enviar informações. A transmissão de informação de um neurônio para outro ou de um neurônio para uma célula não neural ocorre através de estruturas especializadas denominadas sinapses, que podem tanto induzir quanto inibir a despolarização da célula pós-sináptica. Cada neurônio pode ter de mil a 10 mil sinapses físicas e químicas. Nesse local, a informação é passada para o próximo neurônio através de neurotransmissores (MACHADO, 2002).

O processo de aprender está relacionado com as bases químicas e físicas na função neural, através das sinapses. As sinapses físicas relacionam os acontecimentos que vêm do meio externo para o interno, e as sinapses químicas são responsáveis pela comunicação entre neurônios por meio de mediadores químicos denominados neurotransmissores (NT), que são sintetizados pelos próprios neurônios e armazenados dentro de vesículas. Sendo assim, os estados mentais são provenientes de padrões de atividade neural, sendo a aprendizagem realizada por meio da estimulação das conexões neurais que induzem o desenvolvimento e reorganização da estrutura cerebral, resultando em novos comportamentos que acontecem quando ocorre uma efetiva intervenção pedagógica. Por isso, pode-se afirmar que o cérebro que aprende é estimulado anatômica e fisiologicamente. E para compreender como a neurociência contribui com o processo de ensino é preciso conhecer a anatomia da aprendizagem e como as áreas do sistema nervoso são estimuladas e as informações são processadas. Por isso a importância de se conhecer as funções desenvolvidas pela região cerebral denominada córtex.

Do ponto de vista da aprendizagem, a aquisição de conteúdos teóricos está relacionada com várias regiões do encéfalo, sobretudo com estruturas do cérebro e sistema límbico, como o hipocampo, a amígdala e o córtex entorrinal (DALGARRONDO, 2008). O córtex cerebral é a camada mais externa do cérebro, responsável pelas funções mentais mais complexas e desenvolvidas, como memória, atenção, consciência, linguagem, percepção e pensamento; é o local do processamento neuronal. Existem vários graus de organização do córtex cerebral como, por exemplo, lobos, giros e camadas teciduais. Neste estudo escolheu-se utilizar a divisão do córtex em lobos, pois, ainda que mais geral, é mais simples de compreender. O Quadro 1 apresenta a relação entre as regiões do córtex cerebral e suas principais funções.

Quadro1 - Relação entre as regiões do córtex cerebral e suas principais funções

\begin{tabular}{|l|l|}
\hline Região do Córtex Cerebral & \multicolumn{1}{c|}{ Principais Funções } \\
\hline Lobo Frontal & $\begin{array}{l}\text { Responsável pelas funções cognitivas superiores e função } \\
\text { motora. }\end{array}$ \\
\hline Lobo Temporal & $\begin{array}{l}\text { Processa os estímulos auditivos e realiza associações de } \\
\text { informações. }\end{array}$ \\
\hline Lobo Parietal & $\begin{array}{l}\text { É constituído por duas subdivisões: a anterior, denominada } \\
\text { córtex somatossensorial, que é responsável pela recepção de } \\
\text { sensações como o tato, a dor e a temperatura do corpo, e a } \\
\text { área posterior dos lobos parietais, que é uma área secundária } \\
\text { responsável pela análise, interpretação e integração das } \\
\text { informações recebidas pela área anterior. }\end{array}$ \\
\hline Lobo Occiptal (ou visual) & Processa os estímulos visuais. \\
\hline
\end{tabular}

Fonte: Elaborado pelos autores deste trabalho. 
Portanto, a compreensão destas funções se faz necessária na sala de aula, como explicam Guerra, Pereira e Lopes (2004, p. 1):

As estratégias pedagógicas utilizadas pelo educador no processo ensino e aprendizagem são estímulos que reorganizam o sistema nervoso em desenvolvimento, produzindo aquisição de comportamentos, objetivo da educação.

Por isso é fundamental que os professores estimulem individualmente a inteligência dos seus alunos, reconhecendo as diferentes potencialidades, limitações e habilidades que cada indivíduo possui, utilizando diferentes metodologias que possibilitem a cada um aprender da maneira mais efetiva. Esses estímulos podem aumentar sua motivação para a aprendizagem, já que cada indivíduo possui especificidades no processo de aprender (STERNBERG; GRIGORENKO, 2003).

Desta maneira, Markova (2000) defende a importância da neurociência na sala de aula e explica que as pessoas pensam e aprendem de maneiras diferentes, utilizando padrões individuais da inteligência natural que a mente usa para aprender e apresenta seis padrões diferentes de aprendizagem, que se baseiam na forma como as informações são processadas pelo cérebro:

Os 6 padrões de aprendizagem trazidos por Markova estão relacionados com os 3 níveis de consciência (mente consciente, mente subconsciente e mente inconsciente) e com as 3 linguagens simbólicas que a mente usa para receber, organizar e processar informações (auditiva, visual e cinestésica). Cada estado de consciência usa uma das 3 linguagens simbólicas para processar as informações. (GROSSI; SANTOS, 2011, p. 3).

Nesta perspectiva, como existem várias formas de pensar e de aprender, também há várias formas de ensinar. O Quadro 2 apresenta diversas alternativas de estratégias pedagógicas que devem ser escolhidas para despertar as linguagens predominantemente naturais da mente, denominadas por Markova (2000) como linguagens simbólicas responsáveis pela forma como cada aluno aprende. É importante salientar que, durante o processo de aprendizagem, não se utiliza apenas e de uma só vez uma linguagem de aprendizagem, mas a combinação de várias. Portanto, para estimular uma linguagem da mente, várias estratégias pedagógicas são requeridas.

Quadro 2 - As linguagens naturais da mente e as estratégias pedagógicas

\begin{tabular}{|c|l|}
\hline $\begin{array}{c}\text { Linguagem Natural } \\
\text { predominante da Mente }\end{array}$ & \multicolumn{1}{c|}{ Principais Estratégias pedagógicas } \\
\hline Visual & $\begin{array}{l}\text { Portifólio; Seminários; Mapa conceitual; Estudo de caso; } \\
\text { Filmes/vídeos; Leitura; Jogos; Interação via redes sociais. }\end{array}$ \\
\hline Auditiva & $\begin{array}{l}\text { Aula expositiva dialogada; Artes cênicas; Música; Jogos; } \\
\text { Grupo de verbalização e de observação (GVGO); Debates } \\
\text { e júri simulado. }\end{array}$ \\
\hline Cinestésica & $\begin{array}{l}\text { Competições esportivas; Artes cênicas e plásticas; Dança; } \\
\text { Jogos. }\end{array}$ \\
\hline
\end{tabular}

Fonte: Elaborado pelos autores deste trabalho.

O desafio da neurociência aplicada na educação é relacionar as informações dos Quadros 1 e 2, identificando as linguagens naturais predominantes da mente com as ações pedagógicas, que por sua vez irão estimular cada uma das regiões do córtex cerebral. Desta maneira, as práticas pedagógicas poderão ser pautadas pela multiplicidade no aprendizado, em que informações são expostas de maneiras diversas, usando múltiplos métodos. Por exemplo, estudos têm apontado que a diversão pode contribuir com a aprendizagem, pois nestas situações o corpo libera o neurotrasmissor dopamina, responsável pelas sensações de bem-estar e prazer e pelas funções relacionadas com cognição, motivação, recompensa, atenção, humor e aprendizagem. E nas palavras de Relvas (2011, p. 19): 
O avanço dos estudos da Neurociência aplicada escolar é de suma importância para o entendimento das funções corticais superiores envolvidas no processo da aprendizagem. Sabe-se que o indivíduo aprende por meio de modificações funcionais do SNC, principalmente nas áreas da linguagem, das gnosias, das práxis, da atenção e da memória, e, para que o processo de aprendizagem se estabeleça corretamente, é necessário que as interligações entre as diversas áreas corticais e outros níveis sejam integradas efetivamente.

Contudo, este avanço ainda é tímido, embora existam algumas iniciativas, como os projetos que se dedicam à neurociência, tais como:

- Projeto Plural: projeto implementado em 2010, em Ribeirão Preto, pelo Centro Integrado de Psicologia e Educação (CIPE) com apoio e parceria do Instituto de Neurociências e Comportamento ( $\mathrm{INeC}$ ), com o objetivo de promover discussões que tenham como foco os aspectos básicos da neurociência cognitiva aplicada à educação (PROJETO PLURAL, 2011).

- NeuroEduca: projeto de extensão registrado na Pró-reitoria de Extensão da Universidade Federal de Minas Gerais, que visa orientar educadores na utilização do conhecimento das neurociências no ensino e na abordagem dos problemas de aprendizagem. Desta forma, o NeuroEduca tem como objetivo a capacitação e orientação continuada de professores das redes públicas, esfera municipal e estadual, sobre os fundamentos neurobiológicos do processo ensino e aprendizagem e sobre as influências e intervenções neste processo. O projeto tem a participação de graduandos de Medicina e Psicologia da UFMG e ocorre por meio de reuniões periódicas. Ele tem obtido bons resultados, constatados pelo relato de professores participantes que se sentem mais aptos para lidar com as dificuldades e transtornos de aprendizagem (UNIVERSIDADE FEDERAL DE MINAS GERAIS, 2012).

- O Cérebro Vai à Escola: faz parte de um projeto do Instituto de Ciências Biológicas
(ICB) da UFMG sob a forma de Curso de Especialização em Neurociência e Comportamento, além dos seguintes cursos de atualização na área: Aspectos Biológicos Gerais do Sistema Nervoso Central, Fundamentos Básicos de Processos Comportamentais, Envelhecimento Cerebral e Doença de Alzheimer, Dependência Química, Neuropsicofarmacologia e Terapêutica e $\mathrm{O}$ Cérebro Vai à Escola: um diálogo entre a neurociência e a educação (FUNDAÇÃO DE DESENVOLVIMENTO DA PESQUISA, 2011).

- Comunidade Aprender Criança: este projeto é a primeira comunidade acadêmica brasileira dedicada ao aprimoramento do ensino e aprendizado através dos avanços nas pesquisas sobre o cérebro. Tem o objetivo de integrar educadores e neurocientistas, em um trabalho cooperativo, na busca de soluções que aprimorem o ensino e o aprendizado em todos os níveis (COMUNIDADE APRENDER CRIANÇA, 2008).

- Instituto de Pesquisas em Neuroeducação: traz uma abordagem inovadora de trabalho, congregando conhecimentos da Programação Neurolinguística, da Neurociência e da Física da Consciência, e oferece ferramentas de desenvolvimento pessoal que primam pela eficácia de resultados, possibilitando ao ser humano encontrar o equilíbrio necessário para realizar seus projetos de vida. Foi formatado um curso de especialização em Neuroeducação, com o objetivo de capacitar multiplicadores para dar força e movimento ao propósito de materializar a inclusão social através da inclusão escolar, tornando o indivíduo seu próprio instrumento de ascensão social (INSTITUTO DE PESQUISAS EM NEUROEDUCAÇÃO, 2006).

Portanto, os conhecimentos agregados pelas neurociências podem contribuir para um avanço na educação, em busca de melhor qualidade e resultados mais eficientes para a qualidade de vida do indivíduo e da sociedade (COSENZA; GUERRA, 2011, p. 145). 


\section{Metodologia}

Para atingir o objetivo proposto, esta pesquisa foi dividida em quatro tapas. Em todas as etapas a metodologia empregada foi a análise de conteúdo em uma abordagem qualitativa com enfoque descritivo:

$1^{\text {a }}$ etapa: realizada no segundo semestre de 2012. O universo pesquisado foi composto pelos cursos de Pedagogia de instituições públicas e privadas das cinco regiões brasileiras. Foram consultados 465 sites de instituições de ensino, cujo foco foi as matrizes curriculares dos cursos de Pedagogia. Porém a pesquisa ocorreu em 352 matrizes curriculares, pois apenas estas atendiam aos critérios descritos a seguir:

- Credenciamento no Ministério da Educação e Cultura (MEC), com dados disponíveis na plataforma e MEC, do mesmo órgão;

- Existência de sítio eletrônico que disponibilizasse o acesso às matrizes curriculares dos cursos de Pedagogia.

Em relação ao procedimento técnico, foi usado o levantamento por meio de instrumentos de coleta de dados compostos por análise documental e pesquisa bibliográfica.

Das 352 matrizes curriculares pesquisadas, 39 foram da Região Norte, 70 da Nordeste, 29 da Centro-Oeste; 85 da Sudeste e 129 da Região Sul. Ressalta-se que a quantidade de instituições analisadas em cada região foi condizente com o número de instituições credenciadas pelo MEC em cada uma dessas regiões.

$2^{a}$ etapa: realizada no primeiro semestre de 2013. O universo pesquisado foi composto pelos cursos do programa especial de formação pedagógica de docentes das cinco regiões brasileiras. Foram consultados 53 sites de instituições de ensino, cujo foco foi as matrizes curriculares dos cursos do programa especial de formação pedagógica de docentes. Foram utilizados os mesmos critérios da $1^{\text {a }}$ etapa para seleção das matrizes curriculares, sendo 53 delas analisadas.

$3^{\text {a }}$ etapa: realizada no primeiro semestre de 2013. Foi feita uma análise documental a partir do acesso ao portal do Ministério da Educação, com o intuito de verificar a legislação que dispõe sobre as Diretrizes Curriculares dos cursos de graduação em Pedagogia, que são as normas obrigatórias para o Ensino Superior que têm como objetivo orientar o planejamento curricular das instituições buscando promover uma equidade de aprendizagem, possibilitando que conteúdos básicos/ comuns estejam presentes nas matrizes curriculares associados a outros conteúdos aliados à contextualização da instituição.

$4^{\text {a }}$ etapa: realizada no primeiro semestre de 2013. O universo de pesquisa foi composto por publicações acadêmicas sobre o tema pesquisado. Realizou-se uma consulta ao banco de teses e dissertações do Portal da Coordenação de Aperfeiçoamento de Pessoal de Nível superior (Capes) de Periódicos Eletrônicos, com o propósito de identificar o que tem sido produzido sobre a formação do educador e a presença da neurociência na sala de aula, entre os anos de 2000 e 2011. Os descritores adotados para as buscas foram: "formação de docentes e a neurociência"; "neurociência e educação"; "neuroeducação"; "neurociência e processos educativos"; e "neurociências e cursos de Pedagogia".

\section{Resultados e Análise dos dados}

A demonstração dos resultados, bem como suas análises, foi agrupada em quatro itens, de acordo com as etapas da metodologia.

\subsection{Primeira etapa}

Os resultados apresentados na pesquisa (Quadro 3) mostram a presença pouco expressiva da neurociência na formação dos pedagogos. Apenas $6,25 \%$ das instituições pesquisadas contemplavam as disciplinas de neurociência e correlatas nas suas matrizes curriculares. Somando a essa informação, o número de formandos nos cursos de Pedagogia dobrou em sete anos, segundo dados do Censo do Ensino Superior realizado pelo INEP. Em 2002, o levantamento registrou a formatura de 65 mil educadores em pedagogia (BRASIL, 2002); em 2009, esse número subiu para 118 mil (BRASIL, 2009). 
Quadro 3 - Disciplinas relacionadas com a Neurociência e as matrizes curriculares dos cursos de Pedagogia

\begin{tabular}{|c|c|c|c|}
\hline Região & $\begin{array}{l}\text { Número de } \\
\text { instituições } \\
\text { pesquisadas }\end{array}$ & $\begin{array}{c}\text { Número de } \\
\text { instituições que } \\
\text { contemplam a } \\
\text { neurociência nas } \\
\text { matrizes curriculares }\end{array}$ & Disciplinas \\
\hline Norte & 39 & 0 & ---- \\
\hline Nordeste & 70 & 2 & $\begin{array}{l}\text { - Introdução à Neuropisicologia da } \\
\text { Aprendizagem } \\
\text { - Psicolinguística e Alfabetização }\end{array}$ \\
\hline Centro-Oeste & 29 & 0 & ---- \\
\hline Sudeste & 85 & 5 & $\begin{array}{l}\text { - Neuropsicologia do Desenvolvimento } \\
\text { e Educação } \\
\text { - Fundamentos da Neurociência } \\
\text { - Cérebro, mente } \\
\text { - Problemas de Aprendizagem e } \\
\text { Neurociência } \\
\text { - Neurociências e Aprendizagem }\end{array}$ \\
\hline Sul & 129 & 15 & $\begin{array}{l}\text { - Dificuldades de Aprendizagem e } \\
\text { processos neurológicos } \\
\text { - Teorias psicogenéticas de aprendizagem } \\
\text { - Metacognição e motivação para a } \\
\text { aprendizagem } \\
\text { - Processos Neurológicos } \\
\text { - Neuropsicologia } \\
\text { - Linguagem Plástica Visual na } \\
\text { Educação } \\
\text { - Estudos em Linguagem, interação e } \\
\text { cognição } \\
\text { - Fundamentos Psicopedagógicos e } \\
\text { Psiconeurológicos de Aprendizagem } \\
\text { - Linguagem, interação e cognição (I e II) } \\
\text { - Sistema Nervoso e Aprendizagem } \\
\text { - Neurolinguística e Aprendizagem } \\
\text { - Fundamentos Neurobiológicos da } \\
\text { Aprendizagem } \\
\text { - Psicolinguística } \\
\text { - Fundamentos da Neuropsicopatologia } \\
\text { - Cognição e metacognição }\end{array}$ \\
\hline
\end{tabular}

Fonte: Elaborado pelos autores deste trabalho. 
Ainda de acordo com dados do INEP de 2010, o curso de Pedagogia é o curso com maior quantidade de alunos inscritos no país: 273 mil estudantes (BRASIL, 2010). Esses dados reforçam, portanto, a necessidade de capacitar esses profissionais para compreender e atender as diferenças cognitivas dos alunos de acordo com os princípios da neurociência.

\subsection{Segunda etapa}

O universo pesquisado nesta etapa foi composto pelos Programas Especiais de Formação Pedagógica para Docentes. O objetivo desses cursos é habilitar profissionais graduados na modalidade bacharelado, tecnólogos e os professores que já atuam no sistema de ensino fundamental, médio e profissionalizante das redes públicas e privadas em licenciatura plena para ministrar as disciplinas que integram as séries finais do ensino fundamental, médio e a educação profissional nos diferentes sistemas de ensino. O curso é regulamentado pela Resolução CNE/CEB n ${ }^{\circ}$ 02/97, que dispõe sobre os programas especiais de formação pedagógica de docentes para as disciplinas do currículo do ensino fundamental, do ensino médio e da educação profissional em nível médio (BRASIL, 1997).

Foram consultados os sites de 53 instituições brasileiras públicas e privadas que oferecem este curso, mas só foi possível o acesso às matrizes curriculares de 38 instituições. Pela análise das matrizes consultadas, nenhuma das instituições contemplava as disciplinas de neurociência e correlatas em seus cursos. Esses dados revelam que existe uma deficiência na formação do professor quanto ao conhecimento e aplicação da neurociência na educação.

\subsection{Terceira etapa}

De acordo com a Resolução do Conselho Nacional de Educação CNE/CEB n ${ }^{\circ} 1$, de 15 de maio de 2006, que institui Diretrizes Curriculares Nacionais para o curso de graduação em Pedagogia e Licenciatura, percebe-se que existe uma preocupação governamental em formar profissionais da área da educação habilitados para o trato de questões cognitivas dos alunos, como pode ser observado nos artigos $5^{\circ}$ e $6^{\circ}$ desta resolução (BRASIL, 2006):
Art. $5^{\circ} \mathrm{O}$ egresso do curso de Pedagogia deverá estar apto a:

$\mathrm{V}$ - Reconhecer e respeitar as manifestações e necessidades físicas, cognitivas, emocionais, afetivas dos educandos nas suas relações individuais e coletivas.

Art. $6^{\circ}$ A estrutura do curso de Pedagogia, respeitadas a diversidade nacional e a autonomia pedagógica das instituições, constituir-se-á de:

d) utilização de conhecimento multidimensional sobre o ser humano, em situações de aprendizagem;

Assim, verificou-se que nas Diretrizes Curriculares Nacionais para o curso de graduação em Pedagogia há apontamentos para a necessidade dos estudos que abordam as ciências cognitivas. Contudo, percebe-se que não existe uma exigência direta do estudo de temáticas relacionadas às neurociências.

\subsection{Quarta etapa}

A pesquisa realizada no banco de teses e dissertações da Capes (BRASIL, 2013) resultou na identificação dos trabalhos que possuíam relação com as seguintes palavras-chave: "formação de docentes e a neurociência"; "neurociência e educação"; "neuroeducação"; "neurociência e processos educativos"; e "neurociências e cursos de Pedagogia". O resultado da pesquisa foi a identificação de 42 trabalhos, sendo 27 dissertações de Mestrado Acadêmico e 15 teses de Doutorado.

Com base na análise de conteúdo dessas publicações e diante de uma variedade de informações, foram selecionados quatro aspectos considerados relevantes para essa pesquisa: 1) resumo; 2) palavras-chave; 3 ) áreas de conhecimento; e 4) linhas de pesquisa.

Assim, verificou-se que quatro trabalhos, uma tese de Doutorado e três dissertações de Mestrado Acadêmico, mesmo aparecendo na busca, não tinham relação com o tema pesquisado.

Outro resultado evidenciado foi a não ocorrência de trabalhos quando o nível de pesquisa foi o Mestrado Profissional, revelando que o interesse pela temática tem prevalecido no âmbito do Mestrado Acadêmico e no Doutorado, conforme o Gráfico 1. 
Gráfico 1 - Número de teses e dissertações de mestrado identificadas no período de 2000 a 2011 no portal da Capes.

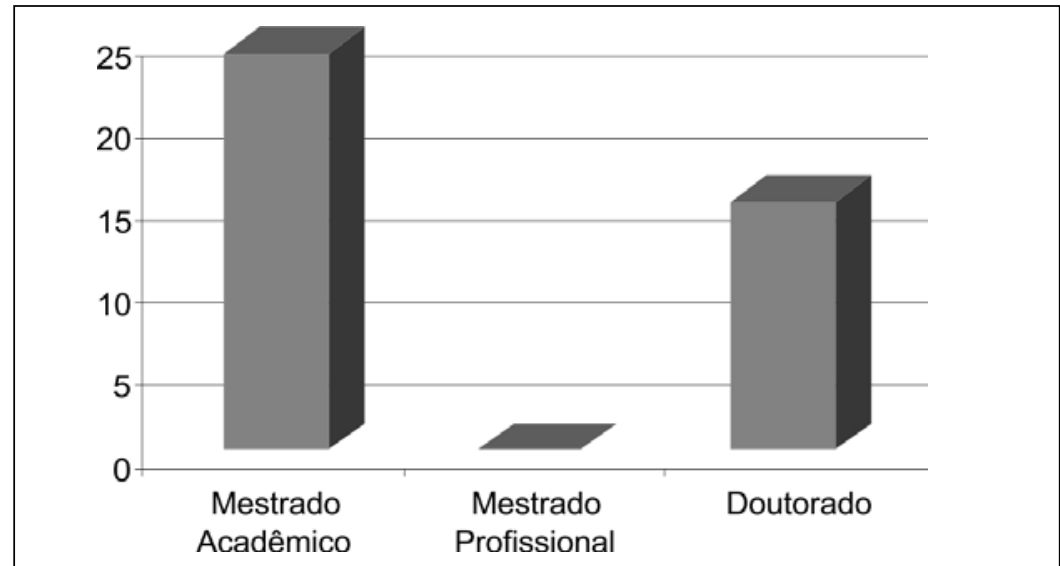

Fonte: Elaborado pelos autores deste trabalho com base no banco de dados do portal Capes.

A análise a partir do ano da publicação (Tabela 1) demonstrou que o interesse pela pesquisa tornou-se constante, aparecendo em todos os anos, exceto em 2002. Contudo, a partir de 2006 houve um aumento no interesse pela temática. $\mathrm{O}$ ano de 2010 destaca-se como o de maior produção sobre o tema pesquisado.

Tabela 1 - Número de teses e dissertações de Mestrado relacionadas ao tema pesquisado - consulta portal da Capes

\begin{tabular}{c|c|c}
\hline Ano & Frequência & $\begin{array}{c}\text { Trabalhos efetivamente } \\
\text { relacionados ao tema } \\
\text { pesquisado }\end{array}$ \\
\hline 2000 & 2 & 2 \\
\hline 2001 & 1 & 0 \\
\hline 2002 & 0 & 0 \\
\hline 2003 & 1 & 0 \\
\hline 2004 & 3 & 3 \\
\hline 2005 & 3 & 3 \\
\hline 2006 & 6 & 6 \\
\hline 2007 & 4 & 4 \\
\hline 2008 & 4 & 4 \\
\hline 2009 & 5 & 3 \\
\hline 2010 & 7 & 7 \\
\hline 2011 & 6 & 6 \\
\hline Total & $\mathbf{4 2}$ & $\mathbf{3 8}$ \\
\hline
\end{tabular}

Fonte: Elaborado pelos autores deste trabalho com base no banco de dados do portal Capes. 
Também foi pesquisado no portal da Capes o número de publicações em periódicos no período de 2000 a 2011. Foram utilizadas nas buscas as mesmas palavras-chave para a pesquisa das teses e dissertações de mestrado e selecionados apenas os trabalhos apresentados em língua portuguesa e em revistas nacionais.

No resultado da pesquisa identificou-se 52 artigos, mas ao analisar o resumo destes concluiu-se que apenas 23 artigos descreviam sobre o tema pesquisado, o que representa $44,23 \%$ da publicação nacional.

Percebe-se, pela Tabela 2, a evolução dessas publicações por ano. Observando esta evolução em relação aos trabalhos que efetivamente abordaram o tema neurociência e educação, a maior parte das publicações concentrou-se de 2009 em diante, representando $60,87 \%$ do total, o que indica um interesse crescente em desenvolver pesquisas nessa área, embora ela ainda seja muito nova e em construção.

Tabela 2 - Número de periódicos relacionados ao tema pesquisado - consulta portal da Capes

\begin{tabular}{c|c|c}
\hline Ano & Frequência & $\begin{array}{c}\text { Trabalhos efetivamente } \\
\text { relacionados ao tema } \\
\text { pesquisado }\end{array}$ \\
\hline 2000 & 0 & 0 \\
\hline 2001 & 1 & 0 \\
\hline 2002 & 0 & 0 \\
\hline 2003 & 1 & 1 \\
\hline 2004 & 0 & 0 \\
\hline 2005 & 1 & 1 \\
\hline 2006 & 2 & 3 \\
\hline 2007 & 2 & 1 \\
\hline 2008 & 3 & 3 \\
\hline 2009 & 11 & 6 \\
\hline 2010 & 10 & 3 \\
\hline 2011 & 8 & 5 \\
\hline Total & $\mathbf{2 9}$ & $\mathbf{2 3}$ \\
\hline
\end{tabular}

Fonte: Elaborado pelos autores deste trabalho com base no banco de dados do portal Capes.

Analisando as quatro etapas, constata-se que tem aumentado o interesse sobre o conhecimento, funcionamento, potencialidades e limitações do sistema nervoso. Entretanto os avanços nos estudos sobre esta área de conhecimento ainda são inexpressivos. A pesquisa também revelou que a incorporação dos conhecimentos relacionados à Neurociência Cognitiva na área educacional não é uma realidade, haja vista a falta de disciplinas sobre este tema na maioria das matrizes curriculares nos cursos de Pedagogia e dos Programas Especiais de Formação Pedagógica de docentes em todo o país, embora pelas Diretrizes curriculares do MEC perceba-se a preocupação em se preparar os profissionais da educação habilitados em reconhecer e respeitar as manifestações e necessidades físicas e cognitivas dos educandos. 


\section{Considerações finais}

Já não é possível ignorar a influência da neurociência no processo de ensino e aprendizagem. A compreensão sobre o funcionamento do cérebro, nas dimensões cognitivas, emocionais, afetivas e motoras, está associada às funções das áreas corticais e também com as linguagens naturais da mente. Assim, as escolhas das estratégias pedagógicas precisam ser pensadas a partir dessa compreensão.

É fundamental que educadores conheçam as interfaces da aprendizagem e que seja sempre um campo a ser explorado. Para isso, os estudos da biologia cerebral vêm contribuindo para a práxis em sala de aula, na compreensão das dimensões cognitivas, motoras, afetivas e sociais no redimensionamento do sujeito aprendente e suas formas de interferir nos ambientes pelos quais perpassam. (RELVAS, 2011, p. 34).

Se o educador tem o conhecimento do funcionamento cerebral e reconhece que cada aluno aprende de uma maneira diferente, estará preparado para desenvolver suas aulas explorando os diferentes estilos de aprendizagem dos alunos e utilizando variadas estratégias pedagógicas, ressignificando sua prática docente (SOARES, 2003).

Todavia, percebeu-se que a neurociência ainda não está presente oficialmente na formação dos pedagogos. De acordo com os resultados desta pesquisa, constatou-se que dos 352 cursos de Pedagogia pesquisados, apenas $6,25 \%$ contemplavam as disciplinas de neurociência e correlatas. Além disso, verificou-se que de todas as instituições brasileiras pesquisadas que oferecem o Programa Especial de Formação Pedagógica para Docentes, nenhuma possui disciplina relacionada com a neurociência, o que permite concluir que o estudo da neurociência na educação ainda não é uma rea- lidade nos cursos de pedagogia nem nos cursos de formação especial de professores.

Esse resultado é preocupante e indica a necessidade de rever os currículos dos profissionais da educação, pois o conhecimento de como o sistema nervoso funciona e sua repercussão no ambiente escolar faz com que o professor reconheça as manifestações e necessidades físicas, cognitivas, emocionais e afetivas dos alunos nas relações individuais e coletivas, além de respeitar as diferenças naturais dos alunos, que refletem em diversas maneiras de aprender, exigindo metodologias de ensino diferenciadas para cada ser humano, levando a uma contribuição positiva na prática pedagógica, minimizando o fracasso escolar e, consequentemente, permitindo que a alfabetização, bem como todo processo de ensino e aprendizagem, seja plenamente efetivado, diminuindo os atuais índices de analfabetos no Brasil.

Contudo, há muito para ser discutido sobre a inclusão de propostas de novas disciplinas nas matrizes curriculares dos cursos analisados neste estudo, pois mesmo no caso das universidades que têm autonomia e um grau de liberdade para organizar sua matriz curricular, existem algumas regras estabelecidas pelo CNE que não podem ser alteradas, como, por exemplo, a carga horária mínima e as disciplinas obrigatórias. Portanto, essa questão deve ser amplamente analisada e discutida em todas as instâncias das universidades e das faculdades.

No que diz respeito à produção nacional, a temática neurociência na educação ainda se encontra tímida, embora haja um interesse cada vez maior, percebido nos últimos dez anos. Conforme os dados apresentados, no Brasil a produção do conhecimento sobre a neurociência apareceu no final da década de 1990, ganhou corpo por volta de 2006 e está crescendo a cada ano.

\section{REFERÊNCIAS}

BRASIL. Ministério da Educação. Instituto Nacional de Estudos e Pesquisas Educacionais Anísio Teixeira. Censo da educação superior de 2010. Disponível em: <http://portal.inep.gov.br/web/censo-da-educacao-superior/ resumos-tecnicos>. Acesso em: 15 out. 2012.

Ministério da Educação. Instituto Nacional de Estudos e Pesquisas Educacionais Anísio Teixeira. Censo da educação superior de 2009. Disponível em: <http://portal.inep.gov.br/web/censo-da-educacao-superior/resumos-tecnicos>. Acesso em: 20 out. 2012.

Ministério da Educação. Instituto Nacional de Estudos e Pesquisas Educacionais Anísio Teixeira. Censo da 
educação superior de 2002. Disponível em: $<$ http://portal.inep.gov.br/web/censo-da-educacao-superior/resumos-tecnicos>. Acesso em: 24 out. 2012.

Ministério da Educação. Resolução CNE/CEB nº 02, de 16 de junho de 1997. Dispõe sobre os programas especiais de formação pedagógica de docentes para as disciplinas do currículo do ensino fundamenta, do ensino médico e da educação profissional profissionalizante em nível médio. Publicado no DOU de 15.07.1997. Disponível em: <http://portal.mec.gov.br/setec/arquivos/pdf/RCNE_CEB02_97.pdf>. Acesso em: 03 nov. 2012.

Ministério da Educação. Resolução CNE/CEB nº 01, de 31 de janeiro de 2006. Altera a alínea "b" do inciso IV do artigo $3^{\circ}$ da Resolução CNE/CEB no 2/98, que instituiu as Diretrizes Curriculares Nacionais para o Ensino Fundamental. Publicado no DOU de 02.02.2006. Disponível em: <http://portal.mec.gov.br/cne/ arquivos/pdf/rceb001_06.pdf>. Acesso em: 03 nov. 2012.

Ministério da Educação. Coordenação de Aperfeiçoamento de Pessoal de Nível Superior (Capes). Periódicos: banco de dados. Disponível em: <http://www.periodicos.capes.gov.br>. Acesso em: mar. 2013.

COMUNIDADE APRENDER CRIANÇA. A primeira comunidade acadêmica no Brasil dedicada ao aprimoramento do ensino e aprendizado através dos avanços nas pesquisas sobre o cérebro. 2008. Disponível em: $<\mathrm{http}: / /$ www.aprendercrianca.com.br/index.php?option $=$ com_content\&view=category\&layout=blog\&id=75\&Ite $\mathrm{mid}=280>$. Acesso em: 20 jan. 2012 .

COSENZA, R; GUERRA, L. Neurociência e educação: como o cérebro aprende. Porto Alegre: Artmed, 2011.

DALGALARRONDO, P. Psicopatologia e semiologia dos transtornos mentais. 2. ed. Porto Alegre: Artmed, 2008.

ESCRIBANO, C. L. Contribuciones de la neurociencia al diagnóstico y tratamiento educativo de la dislexia del desarrollo. Revista de Neurología, Barcelona, v. 44, n. 3, p. 173-180, 2007.

FUNDAÇÃO DE DESENVOLVIMENTO DA PESQUISA (FUNDEP). Galeria de projetos. Neurociência e comportamento. Curso de especialização em neurociência e comportamento. Belo Horizonte, 2011. Disponível em: $<\mathrm{http}$ :/galeriadeprojetos.fundep.br/projeto/projeto_detalhe.aspx?tipo=1\&area=1\&id=63>. Acesso em: 09 jan. 2012.

GROSSI, M. G. R.; SANTOS, A. J. As contribuições de Paulo Freire e Howard Gardner e das novas tecnologias na Educação. In: CONGRESSO INTERNACIONAL DE EDUCAÇÃ̃, 3., 2011, Ponta Grossa, PR. Anais eletrônicos... Ponta Grossa, PR: Instituto Sul Americano de Pós-Graduação, Ensino e Tecnologia,

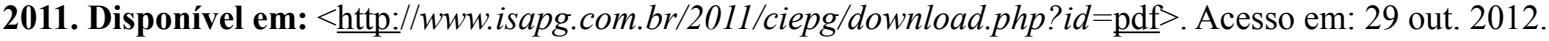

GUERRA, L. B. Como as neurociências contribuem para e educação escolar? FGR em revista, Belo Horizonte, ano 4, n. 5, p. 6-9, out. 2010. Disponível em: <http://www.fgr.org.br/site/revistas/revista_5edicao.pdf $>$. Acesso em: 02 dez. 2012.

GUERRA, L. B.; PEREIRA, A. H.; LOPES, M. Z. Neuroeduca - inserção da neurobiologia na educação. In: ENCONTRO DE EXTENSÃO DA UNIVERSIDADE FEDERAL DE MINAS GERAIS, 7., 2004, Belo Horizonte. Anais eletrônicos... Belo Horizonte: Universidade Federal de Minas Gerais, 2004. Disponível em: <http://www. ufmg.br/proex/arquivos/7Encontro/Educa113.pdf>. Acesso em: 20 out. 2012.

INSTITUTO DE PESQUISAS EM NEUROEDUCAÇÃO. Quem somos. São Paulo, 2006. Disponível em: <http:// www.neuroeducacao.com.br/quemsomos.asp>. Acesso em: 20 jan.2013.

MACHADO, A. Neuroanatomia funcional. 2. ed. São Paulo: Atheneu, 2002.

MARKOVA, D O natural e ser inteligente: padrões básicos de aprendizagem a serviço da criatividade e educação. São Paulo: Summus, 2000.

METRING, R. Neuropsicologia e aprendizagem: fundamentos necessários para planejamento do ensino. Rio de Janeiro: Wak, 2011.

PEARSON. The learning curve. London, 2012. Disponível em: $<$ http://thelearningcurve.pearson.com>. Acesso em: 27 nov. 2012.

PROJETO PLURAL. Revista Plural, Ribeirão Preto, SP, v. 2, p. 1, jan. 2011. Disponível em: <http://pluralgep. files.wordpress.com/2011/02/revistaplural2011_atualizada.pdf $>$. Acesso em: 05 ago. 2012.

RELVAS, M. P. Neurociência e transtornos de aprendizagem: as múltiplas eficiências para uma educação inclusiva. 5. ed. Rio de Janeiro: Wak, 2011. 
SOARES, D. Os vínculos como passaporte da aprendizagem: um encontro D’EUS. Rio de Janeiro: Caravansarai, 2003.

STERNBERG, R. J.; GRIGORENKO, E. L. Inteligência plena: ensinando e incentivando a aprendizagem e a realização dos alunos. Porto Alegre: Artmed, 2003.

UNIVERSIDADE FEDERAL DE MINAS GERAIS. Instituto de Ciências Biológicas. NeuroEduca. Belo Horizonte, 2012. Disponível em: <http://www.icb.ufmg.br/neuroeduca>. Acesso em: 05 ago. 2011.

Recebido em: 06.12 .13

Aprovado em: 17.02.14 